\title{
Fabrication of PLGA nanoparticles with a fluidic nanoprecipitation system
}

\author{
Hui Xie, Jeffrey W Smith*
}

\begin{abstract}
Particle size is a key feature in determining performance of nanoparticles as drug carriers because it influences circulating half-life, cellular uptake and biodistribution. Because the size of particles has such a major impact on their performance, the uniformity of the particle population is also a significant factor. Particles comprised of the polymer poly(lactic-co-glycolic acid) (PLGA) are widely studied as therapeutic delivery vehicles because they are biodegradable and biocompatible. In fact, microparticles comprised of PLGA are already approved for drug delivery. Unfortunately, PLGA nanoparticles prepared by conventional methods usually lack uniformity. We developed a novel Fluidic NanoPrecipitation System (FNPS) to fabricate highly uniform PLGA particles. Several parameters can be fine-tuned to generate particles of various sizes.
\end{abstract}

\section{Background}

Particles comprised of the polymer poly(lactic-co-glycolic acid) (PLGA) are widely studied as therapeutic delivery vehicles because they are biodegradable [1] and biocompatible [2-4]. In fact, microparticles comprised of PLGA are already approved for establishing sustained release of leuprolide (Lupron Depot) and triptorelin (Trelstar). Similar PLGA particles also show promise as a delivery vehicle for proteins [5,6], siRNA [7], and for presenting antigens to dendritic cells for vaccination [8-10]. It is also becoming clear that PLGA particles offer considerable flexibility in choosing a route of delivery because they have proven to be effective when injected intramuscularly [11,12], when delivered via inhalation [13-15], and recent results indicate that they also have promise for oral delivery of drugs and antigens [16-19].

Particle size is one of the key features in determining performance because it influences circulating half-life, cellular uptake and biodistribution [20-22]. The kinetic aspects of drug release are also strongly influenced by particle size [23-25]. Early interest in drug-loaded particles centered on their application as vehicles for sustained drug release, but now there is great interest in using similar particles for targeting the delivery of drugs to specific tissues, vascular beds, and cells. For the latter

\footnotetext{
* Correspondence: jsmith@burnham.org

Sanford-Burnham Medical Research Institute, 10901 North Torrey Pines Road,
} La Jolla, CA 92037 USA application smaller particles, particularly those in the range of $\sim 100 \mathrm{~nm}$, are likely to be advantageous because they are taken up by cells at rates 15 to 250 fold greater than micron size particles [26]. This difference in the rate of uptake can be the distinction between specific and non-specific uptake. For example, PLGA nanoparticles targeted to dendritic cells with an antibody are taken up specifically, but microparticles targeted with the same antibody are taken up non-specifically [8]. The uniformity of the particle population is also a significant factor in performance. Preparations of particles that are highly uniform will exhibit more consistent biodistribution, cellular uptake, and drug release. Preparations of particles lacking uniformity will exhibit variance in all of these parameters, making it difficult to draw conclusions about which subset of the particle population is responsible for biological effect.

There are many different methods of fabricating solid polymeric particles. Gas flow focusing [27] and electrospray $[28,29]$ can be used to fabricate PLGA microparticles with uniform sizes but these approaches have not been widely used to generate nanoparticles. Several solvent-based methods can be used to make polymeric nanoparticles including interfacial polymerization [30], the evaporation of emulsions [31] and nanoprecipitation [32]. In most cases however, these flow based approaches lack precise control at the macro level, so they yield particles with a broad size distribution. Consequently, extra steps such as filtration or centrifugation 
are required to isolate the population with the desired size [33]. One solution to this problem is the application of microfluidic platforms, which provide extremely precise control over most aspects of the mixing and precipitation process. For example, Karnik et al. developed an elegant microfluidic system that precipitates PLGA nanoparticles by focusing the flow of PLGA in organic solvent by two intersecting streams of aqueous solvent [34]. With this approach highly uniform PLGA particles with diameters of less than $50 \mathrm{~nm}$ could be fabricated.

The use of microfluidic devices is not without limitations though. As Quevedo et al. pointed out, such devices require specialized fabrication procedures and materials that are not widely available, and they can be easily clogged by particle debris [30]. As an alternative, Quevedo et al. proposed a rather simple fluidic system capable of establishing flow conditions suitable for production of monodisperse particles [30]. The utility of the device was demonstrated by using the device to enact interfacial polymerization during flow to produce hollow polyamide shells with diameters ranging from 300-800 $\mu \mathrm{m}$, depending on polymer concentration and flow rates. Here we show that a similar system, without dramatic reductions in dimension, can be applied to enact an entirely different process, nanoprecipitation.

\section{Results and Discussion}

Highly uniform PLGA particles with diameters in the range of 140-500 nm, 1000-fold smaller than those generated by Quevedo et al., can be generated with the
Fluidic Nanoprecipitation System (FNPS). The FNPS can be constructed with general lab equipment and supplies. An inlet channel (26s needle) inserts into the center of a dispersing channel (Tygon tubing with ID 3/ 32") (Figure 1). Flow through each channel can be maintained with peristaltic pumps. A major advantage of this flow-based system is that all of the PLGA droplets are created from the end of the inlet channel under precisely the same conditions (e.g. flow rate, injection rate, polymer concentration, etc.).

Because the preparation and characterization of welldefined sizes of particles remain a challenge, the performance of this system was gauged by comparing PLGA particles fabricated using the FNPS (Figure 2A) to the conventional nanoprecipitation method (Figure 2B). Particles fabricated by the FNPS have a diameter of $148 \pm$ $14 \mathrm{~nm}$, but particles fabricated by the conventional nanoprecipitation method, using the same solvents and polymer concentrations, are $211 \pm 70 \mathrm{~nm}$ in diameter. Importantly, the size uniformity of the PLGA particles fabricated using the FNPS is such that all the particles fall within the 100 to $190 \mathrm{~nm}$ diameter range, and 70\% are between 130 and $160 \mathrm{~nm}$; the particles fabricated using the conventional method have a much broader size distribution, with only $26 \%$ having a diameter of 190 to $220 \mathrm{~nm}$ (Figure 2C). In order to obtain nanoparticles with small size distribution from conventional nanoprecipitation methods, a filtration step is usually necessary; Gaumet et al. reported that as much as 95\% of the particles can be lost during filtration [35]. Because
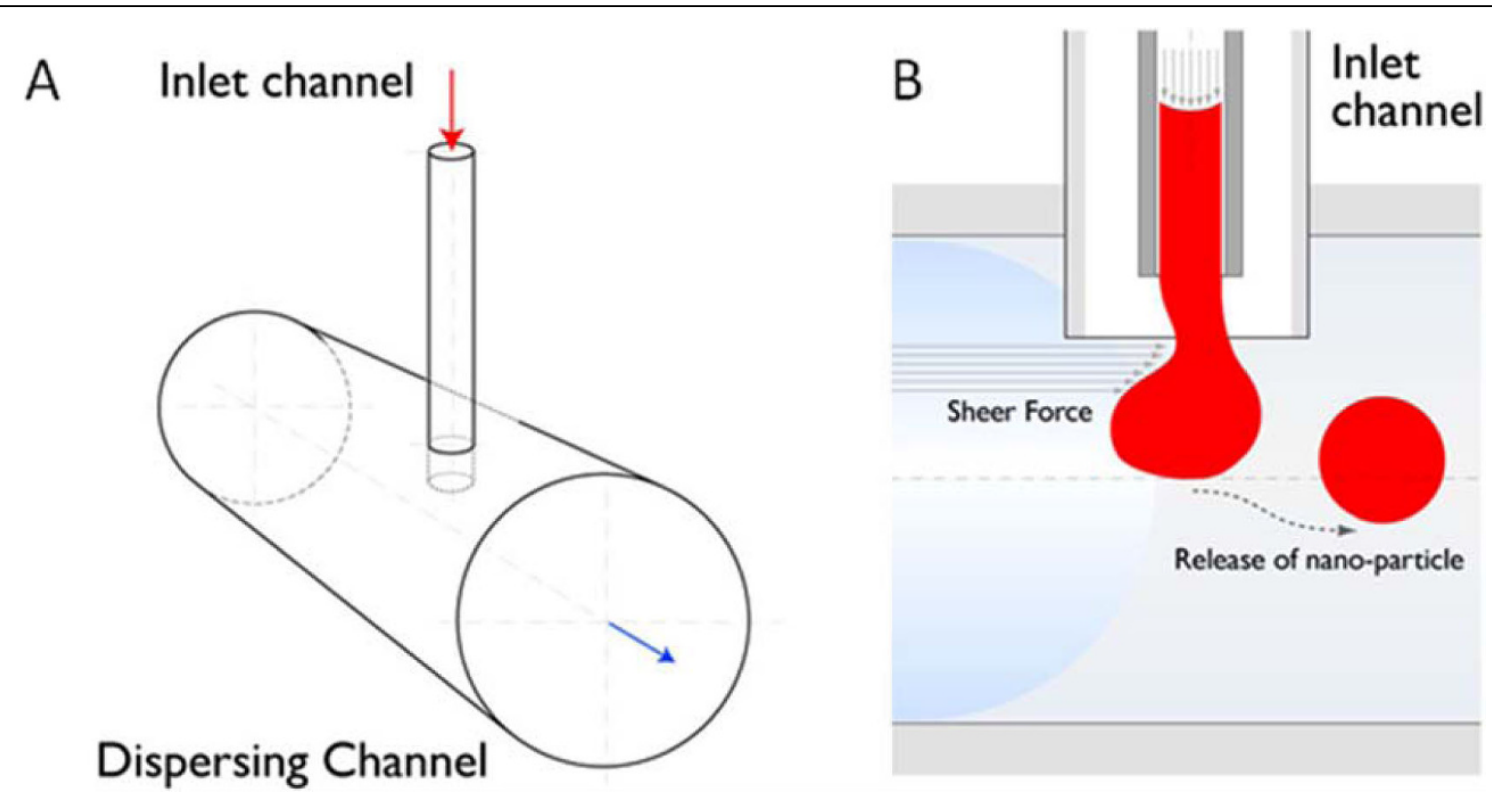

Figure 1 A schematic of the Fluidic NanoPrecipitation System (FNPS). (A) Cartoon of FNPS. Sample inlets are inserted into the dispersing channel. The inlet channel contains PLGA polymer that precipitates upon contact with the surfactant in the dispersing channel, freezing the particles in a spherical morphology. (B) Side view of the channel. PLGA droplets are exposed to the hydrodynamic force of the continuous flow. 

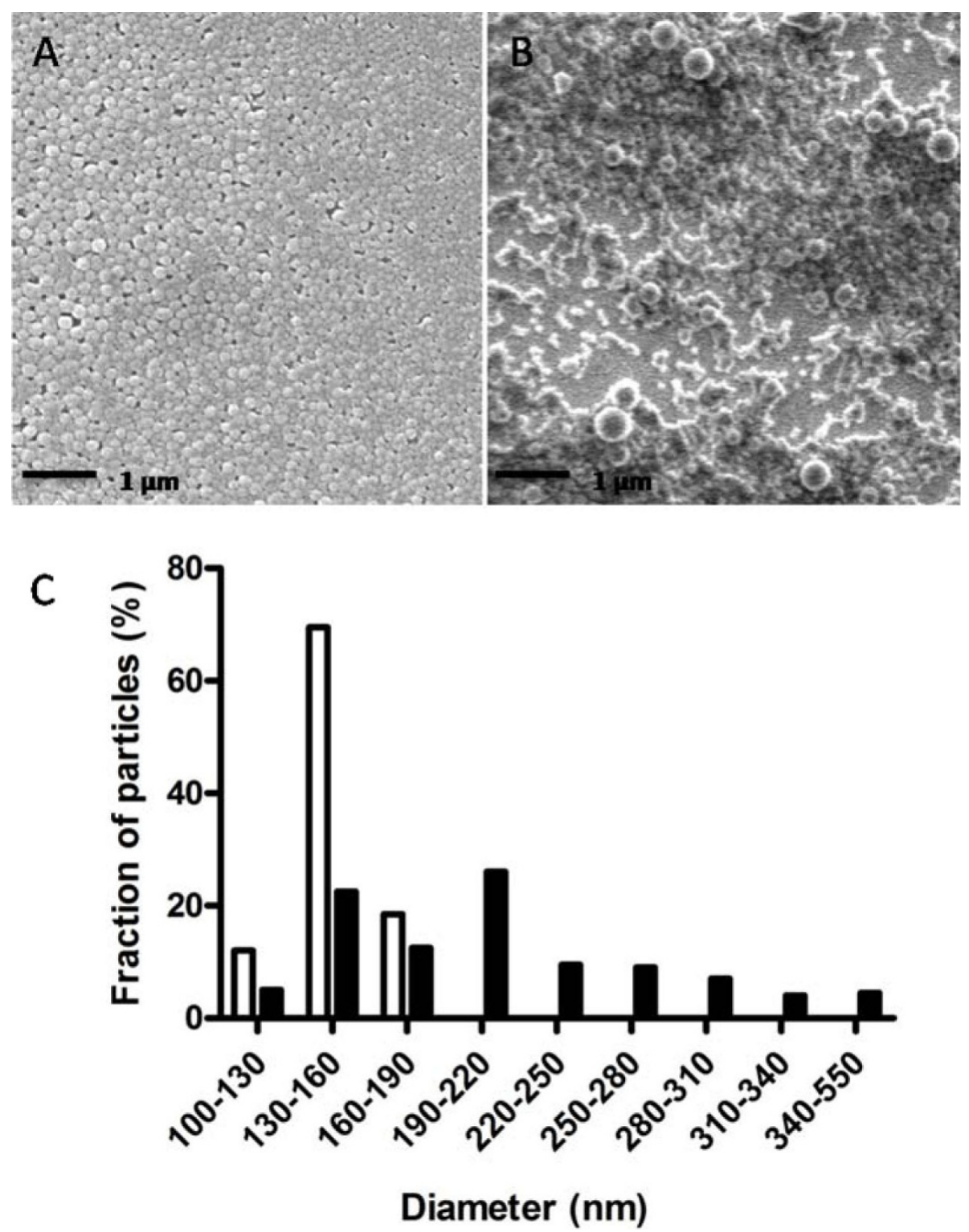

Figure 2 Highly uniform PLGA nanoparticles are fabricated by the Fluidic NanoPrecipitation System (FNPS). Scanning Electron Microscopy (SEM) images of PLGA nanoparticles fabricated by the (A) FNPS, or the (B) conventional nanoprecipitation method. (C) Diameters of the particles were measured by using ImageJ. For each sample, the mean diameter was calculated based on the measurements of 200 randomly chosen particles. White bars indicate the distribution of diameters observed for PLGA nanoparticles fabricated by FNPS (average diameter $148 \pm$ $14 \mathrm{~nm}$ ). Black bars indicate the distribution of diameters for PLGA nanoparticles fabricated by the traditional nanoprecipitation method (average diameter $211 \pm 70 \mathrm{~nm}$ ). Samples were imaged without prior filtration.

of the small size distribution of the nanoparticles generated using FNPS, filtration is not required prior to use.

The size of PLGA particles generated with the FNPS can be changed by adjusting the flow rate of the dispersing phase. For example, a shift from a flow rate of 35 $\mathrm{ml} /$ minute to $50 \mathrm{ml} /$ minute and then to $80 \mathrm{ml} /$ minute decreased particle size from $327 \pm 19 \mathrm{~nm}$ to $278 \pm 35$ and then to $193 \pm 19 \mathrm{~nm}$ (Figure 3A). Similarly, a decrease in PLGA concentration from $40 \mathrm{mg} / \mathrm{ml}$ to 20 $\mathrm{mg} / \mathrm{ml}$ and then to $10 \mathrm{mg} / \mathrm{ml}$ resulted in a reduction in particle diameter from $393 \pm 38 \mathrm{~nm}$ to $327 \pm 19 \mathrm{~nm}$ to $231 \pm 35 \mathrm{~nm}$ (Figure 3B). Since the FNPS is a water/ water miscible solvent system, the composition of the dispersing phase can also be used to control the size of the particles. Increasing the concentration of methanol in the dispersing phase from $20 \%$ to $50 \%$ and then to $80 \%$, coincided with the reduction in particle size from $512 \pm 45 \mathrm{~nm}$ to $315 \pm 36 \mathrm{~nm}$ and then to $148 \pm 14 \mathrm{~nm}$ 


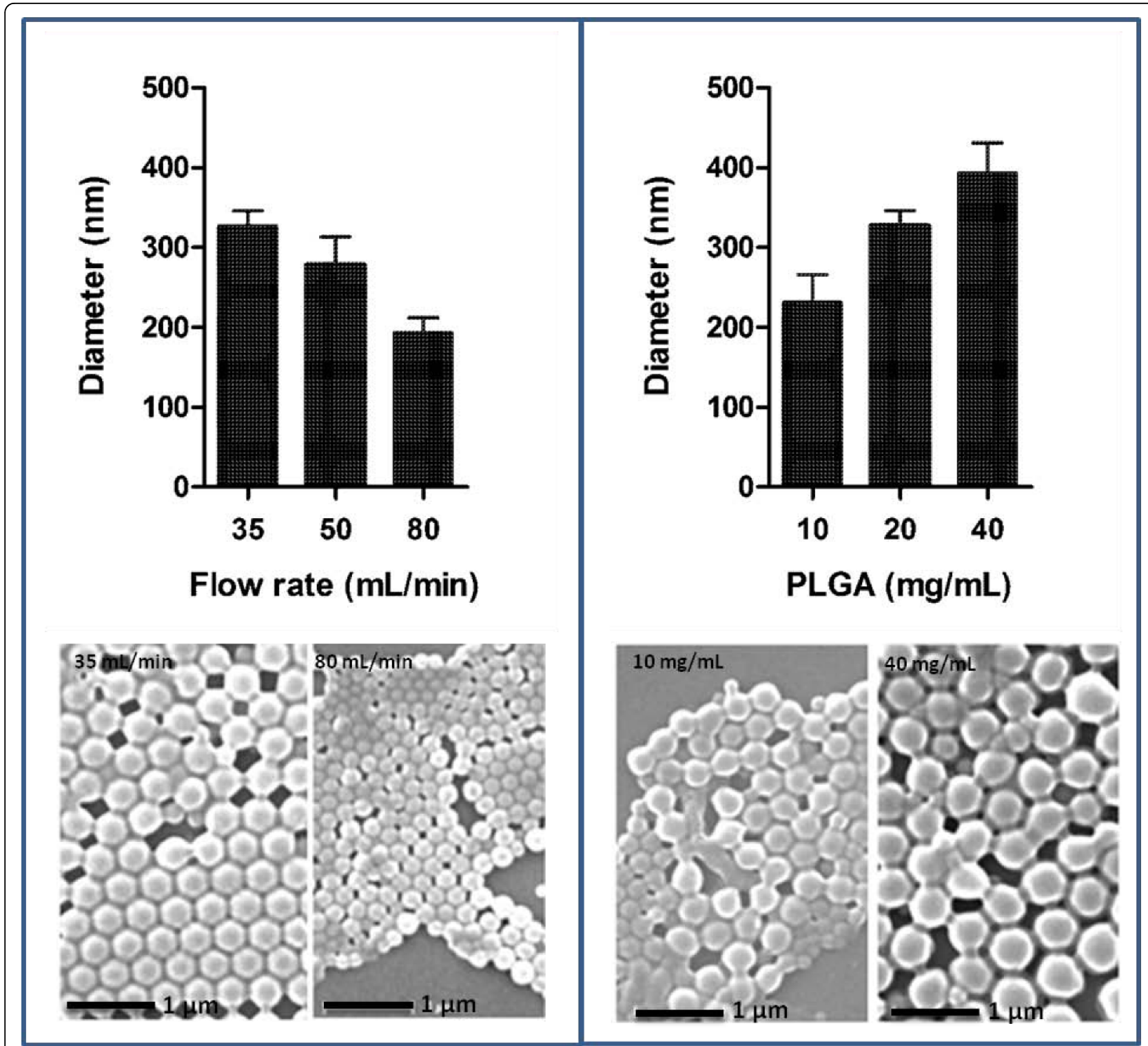

Figure 3 The diameter of PLGA nanoparticles can be controlled by the flow rates and PLGA concentrations. (A) SEM images and diameters of PLGA nanoparticles fabricated at dispersing flow rates of $35 \mathrm{ml} / \mathrm{min}, 50 \mathrm{ml} / \mathrm{min}$, and $80 \mathrm{ml} / \mathrm{min}$. (B) SEM images and diameters of PLGA fabricated at PLGA concentrations of $10 \mathrm{mg} / \mathrm{ml}, 20 \mathrm{mg} / \mathrm{ml}$, and $40 \mathrm{mg} / \mathrm{ml}$. Diameters were measured by using ImageJ. For each sample, the mean diameter was calculated based on the measurements of 100 randomly chosen particles. Samples are imaged without filtration.

(Figure 4). These data suggest that by optimizing all three of these parameters, the FNPS has the flexibility to generate uniform particles across a wide range of sizes from below $100 \mathrm{~nm}$ to above $1 \mu \mathrm{m}$.

The yield of particles is another important aspect of any fabrication method. We found that the yield of particles from the FNPS is typically $80 \%$ of the mass of the PLGA in the inlet solution. Consequently, under the various conditions used for this study, the FNPS generated between two and eight $\mathrm{mg}$ of particles $/ \mathrm{ml} / \mathrm{hr}$. This compares favorably with the yield of three $\mathrm{mgs} / \mathrm{ml} / \mathrm{hr}$ fabricated using similar concentrations of PLGA by the microfluidic system reported by Karnik et al. [34]. The FNPS has many advantages including the ability to scale up production by simply increasing the number of inlets entering the dispersing phase. The dispersing stream could also be recirculated to increase the final concentration of particles in the fluid. In addition, because the devise has a low risk of clogging, it can be used continuously.

The mechanism by which the FNPS is able to generate such small and uniform particles is worthy of discussion. One factor that influences the final size of the solidified particles is the size of the monodisperse droplets from 

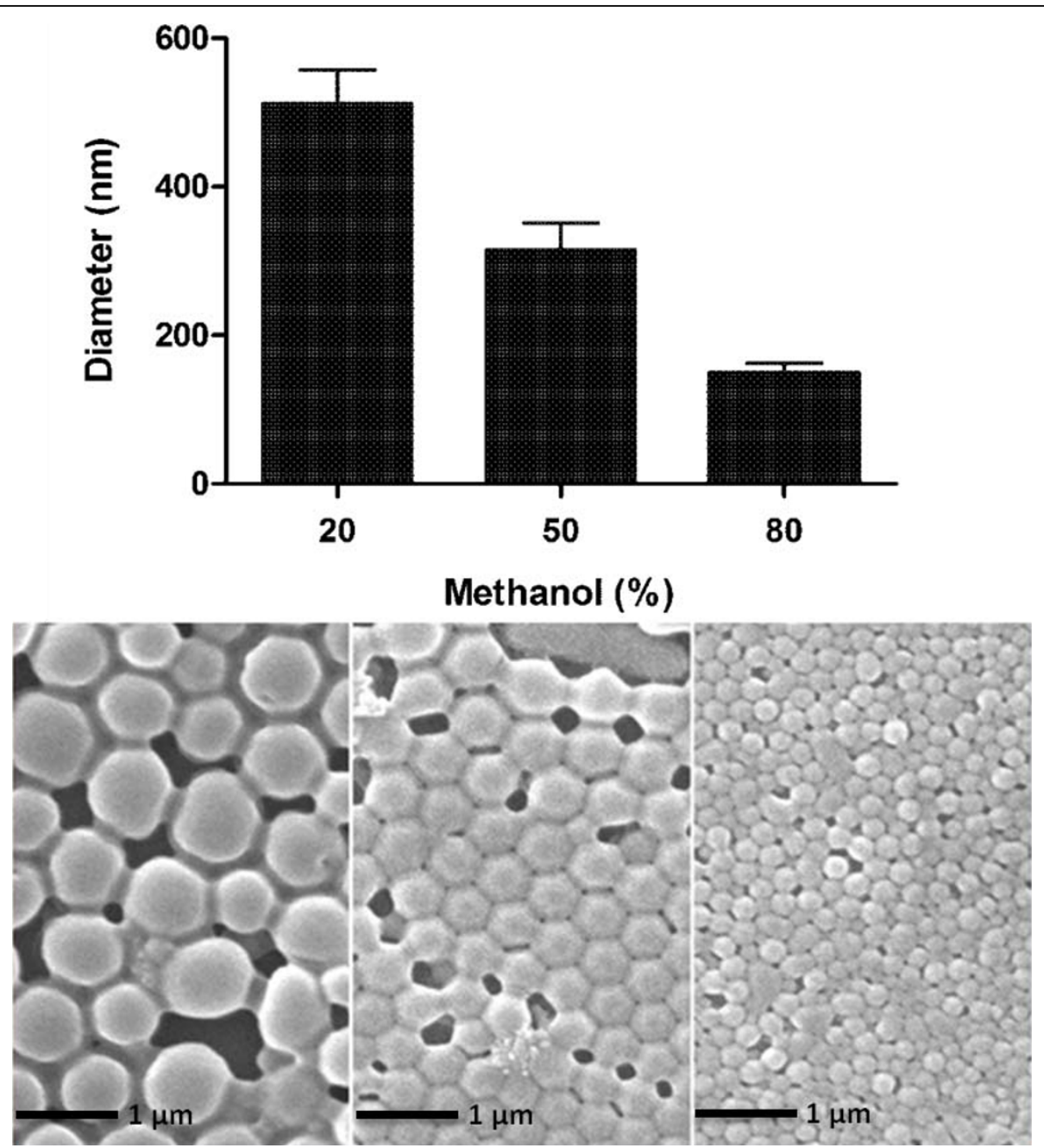

Figure 4 The diameter of PLGA nanoparticles can be controlled by varying the methanol concentrations ( $v / v)$ in the dispersing phase. Diameter of PLGA nanoparticles fabricated using $20 \%, 50 \%$ or $80 \% \mathrm{v} / \mathrm{v}$ methanol in the dispersing phase of the FNPS. The flow rate of the dispersing channel was maintained at $50 \mathrm{ml} /$ minute. Samples were imaged by SEM without prior filtration. The diameter of the particles was calculated by using ImageJ. For each sample, the mean diameter was calculated based on the measurements of 100 randomly chosen particles.

which they are precipitated. Quevedo et al. [30] demonstrated that the flow in a fluidic system with dimensions similar to that used here is comparable to a traditional microfluidic system. They also found that a higher Reynolds number favors the formation of smaller droplets. So then, parameters like the flow rate in the dispersing channel, and the liquid composition within that channel will impact Reynolds number and can be used to control the size of droplets. These conclusions are entirely consistent with our observation that the flow rate alters the final particle size.

The actual process of nanoprecipitation will also influence particle size. This is how our approach differs from that of Quevedo et al. [30]. They used the T-junction system to assist in the precipitation of emulsions that were subsequently made solid by interfacial polymerization via the action of a cross-linker in the dispersing channel. This process creates "hollow" particles with diameters of several hundred microns. In contrast, we directly precipitated the PLGA polymer by rapid solvent exchange, also called nanoprecipitation [32]. The mechanism of particle formation during nanoprecipitation is not entirely understood, meaning that the precise outcome cannot be predicted. Nevertheless, as has been previously discussed [32], nanoprecipitation appears to be governed by the Marangoni effect, wherein movement in an interface is caused by longitudinal variations of interfacial tension [36]. In such a case, precipitation is driven by i) solute transfer out of the phase of higher viscosity, which is influenced by high concentration gradients at the interface; and ii) by interfacial tension, which, in the case of the FNPS, is determined by 
turbulence resulting from flow in the dispersing channel. Consequently, the size of the final particle will be influenced not only by features of the dispersing channel related to Reynolds number, but also by factors that influence interfacial tension. These include the polymer concentration, the presence and concentration of surfactant [37], and the nature of any payload that is co-precipitated into the particles [37]. The depth of insertion of the inlet into the dispersing channel might also influence particle size and geometry due to altered turbulence. However, with this prototype FNPS, it was impossible to test this possibility because we could not control the depth of insertion with great precision.

\section{Conclusions}

In summary, the FNPS described here provides an approach to produce very small and highly uniform polymeric particles, in the absence of sophisticated instrumentation or a microfluidic system. The particles are suitable for multiple uses including drug and imaging agent encapsulation.

\section{Materials and methods Materials}

PLGA Resomer RG502H was purchased from Boehringer-Ingelheim (Ingelheim, Germany). PLGA sample solutions were prepared by dissolving PLGA in acetonitrile. For example, a $40 \mathrm{mg} / \mathrm{ml}$ PLGA solution was pre-

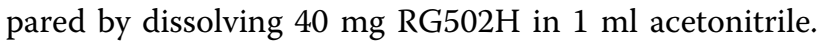
Polyvinyl alcohol (PVA, 87\%-89\% hydrolyzed) was purchased from Sigma-Aldrich. 1\% PVA solution was prepared by dissolving $1 \mathrm{~g}$ PVA in $100 \mathrm{ml}$ DI water at room temperature and filtered to remove any particulate matter.

\section{Device fabrication and experimental setup}

A Fluidic NanoPrecipitation System (FNPS) was fabricated by inserting a stainless steel needle (Hamilton HA-91039 26s syringe needle) with an inner diameter $0.11 \mathrm{~mm}$, into a Tygon ${ }^{\circledR}$ tubing (ID 3/32', OD 5/32') that was used to pass the dispersing phase. The needle was inserted to the interior at $50 \%$ of the tubing diameter.

The PLGA solution fed into the dispersing channel with a $3 \mathrm{ml}$ syringe controlled by a single syringe pump (KDS100, KD Scientific, Massachusetts, USA). A stream of surfactant (1\% PVA solution, $20 \mathrm{ml}$ ) passing through the dispersing channel (Tygon ${ }^{\circledR}$ tubing with ID 3/32', and OD 5/32') was controlled by a Fisher Scientific Variable-Flow Peristaltic Pump.

Nanoparticles were prepared starting with 10 and 40 $\mathrm{mg} / \mathrm{ml}$ of PLGA RG502H polymers in acetonitrile. Samples $(0.2 \mathrm{ml})$ were injected at a flow rate of $3.2 \mu \mathrm{l} / \mathrm{min}$. Nanoparticles were collected into a beaker for analysis.
The nanoparticles were washed by centrifuging for 15 minutes using an Eppendorf 5415R at $13200 \mathrm{rpm}$ at room temperature and then removing the supernatant. The nanoparticles were resuspended in DI water by bath sonication (Branson's Model B200). This was repeated three times and the final suspension was sent for analysis.

\section{Scanning Electron Microscope (SEM)}

SEM experiments were conducted by depositing the nanoparticle suspension on freshly cleaved mica and allowing them to dry. A thin film of Au was sputtered onto these mica substrates with sample. Samples were imaged with scanning electron microscopy (SEM; JEOL $5800 \mathrm{LV}$ ) without filtration or purification. Particle size was measured by using ImageJ. For each sample, the mean diameter was calculated based on the measurements of 100 randomly chosen particles.

\section{Acknowledgements}

The work described in this manuscript was supported by a grant from the U.S. National Institutes of Health (HL080718) awarded to JWS.

\section{Authors' contributions}

JWS and HX conceived and designed the experimental strategy and interpreted the findings.

HX performed all experiments. All authors read and approved the final manuscript.

\section{Competing interests}

The authors declare that they have no competing interests.

Received: 15 March 2010 Accepted: 13 August 2010

Published: 13 August 2010

\section{References}

1. Shive MS, Anderson JM: Biodegradation and biocompatibility of PLA and PLGA microspheres. Adv Drug Deliv Rev 1997, 28:5-24.

2. Fournier E, Passirani C, Montero-Menei CN, Benoit JP: Biocompatibility of implantable synthetic polymeric drug carriers: focus on brain biocompatibility. Biomaterials 2003, 24:3311-3331.

3. Middleton JC, Tipton AJ: Synthetic biodegradable polymers as orthopedic devices. Biomaterials 2000, 21:2335-2346.

4. Wu L, Ding J: In vitro degradation of three-dimensional porous poly(D,Llactide-co-glycolide) scaffolds for tissue engineering. Biomaterials 2004, 25:5821-5830.

5. Giteau A, Venier-Julienne MC, Aubert-Pouessel A, Benoit JP: How to achieve sustained and complete protein release from PLGA-based microparticles? Int J Pharm 2008, 350:14-26.

6. Mundargi RC, Babu VR, Rangaswamy V, Patel P, Aminabhavi TM: Nano/ micro technologies for delivering macromolecular therapeutics using poly(D,L-lactide-co-glycolide) and its derivatives. J Control Release 2008, 125:193-209.

7. Campolongo MJ, Luo D: Drug delivery: Old polymer learns new tracts. Nat Mater 2009, 8:447-448.

8. Cruz LJ, Tacken PJ, Fokkink R, Joosten B, Stuart MC, Albericio F, Torensma R, Figdor CG: Targeted PLGA nano-but not microparticles specifically deliver antigen to human dendritic cells via DC-SIGN in vitro. J Control Release 2010, 144:118-126.

9. Jaganathan KS, Vyas SP: Strong systemic and mucosal immune responses to surface-modified PLGA microspheres containing recombinant hepatitis B antigen administered intranasally. Vaccine 2006, 24:4201-4211.

10. Thomas C, Gupta V, Ahsan F: Influence of surface charge of PLGA particles of recombinant hepatitis $B$ surface antigen in enhancing systemic and mucosal immune responses. Int J Pharm 2009, 379:41-50. 
11. Sirsi SR, Schray RC, Wheatley MA, Lutz GJ: Formulation of polylactide-coglycolic acid nanospheres for encapsulation and sustained release of poly(ethylene imine)-poly(ethylene glycol) copolymers complexed to oligonucleotides. I Nanobiotechnology 2009, 7:1.

12. Zhang YM, Yang F, Yang YQ, Song FL, Xu AL: Recombinant interferonalpha2b poly(lactic-co-glycolic acid) microspheres: pharmacokineticspharmacodynamics study in rhesus monkeys following intramuscular administration. Acta Pharmacol Sin 2008, 29:1370-1375.

13. Jensen DM, Cun D, Maltesen MJ, Frokjaer S, Nielsen HM, Foged C: Spray drying of siRNA-containing PLGA nanoparticles intended for inhalation. J Control Release 2010, 142:138-145.

14. Sivadas N, O'Rourke D, Tobin A, Buckley V, Ramtoola Z, Kelly JG, Hickey AJ, Cryan SA: A comparative study of a range of polymeric microspheres as potential carriers for the inhalation of proteins. Int J Pharm 2008, 358:159-167.

15. Ungaro F, d'Emmanuele di Villa Bianca R, Giovino C, Miro A, Sorrentino R, Quaglia F, La Rotonda MI: Insulin-loaded PLGA/cyclodextrin large porous particles with improved aerosolization properties: in vivo deposition and hypoglycaemic activity after delivery to rat lungs. J Control Release 2009, 135:25-34.

16. Li X, X Y Y, Chen G, Wei P, Ping Q: PLGA nanoparticles for the oral delivery of 5-Fluorouracil using high pressure homogenizationemulsification as the preparation method and in vitro/in vivo studies. Drug Dev Ind Pharm 2008, 34:107-115.

17. Naha PC, Kanchan V, Manna PK, Panda AK: Improved bioavailability of orally delivered insulin using Eudragit-L3OD coated PLGA microparticles. J Microencapsul 2008, 25:248-256.

18. Pandey R, Khuller GK: Nanoparticle-based oral drug delivery system for an injectable antibiotic - streptomycin. Evaluation in a murine tuberculosis model. Chemotherapy 2007, 53:437-441.

19. Shaikh J, Ankola DD, Beniwal V, Singh D, Kumar MN: Nanoparticle encapsulation improves oral bioavailability of curcumin by at least 9 fold when compared to curcumin administered with piperine as absorption enhancer. Eur J Pharm Sci 2009, 37:223-230.

20. Decuzzi P, Pasqualini R, Arap W, Ferrari M: Intravascular delivery of particulate systems: does geometry really matter? Pharm Res 2009, 26:235-243.

21. Gratton SE, Ropp PA, Pohlhaus PD, Luft JC, Madden VJ, Napier ME, DeSimone JM: The effect of particle design on cellular internalization pathways. Proc Natl Acad Sci USA 2008, 105:11613-11618.

22. Gu F, Zhang L, Teply BA, Mann N, Wang A, Radovic-Moreno AF, Langer R, Farokhzad OC: Precise engineering of targeted nanoparticles by using self-assembled biointegrated block copolymers. Proc Natl Acad Sci USA 2008, 105:2586-2591.

23. Siepmann J, Gopferich A: Mathematical modeling of bioerodible, polymeric drug delivery systems. Adv Drug Deliv Rev 2001, 48:229-247.

24. Tamber $\mathrm{H}$, Johansen $\mathrm{P}$, Merkle HP, Gander B: Formulation aspects of biodegradable polymeric microspheres for antigen delivery. Adv Drug Deliv Rev 2005, 57:357-376.

25. Tracy MA, Ward KL, Firouzabadian L, Wang Y, Dong N, Qian R, Zhang Y: Factors affecting the degradation rate of poly(lactide-co-glycolide) microspheres in vivo and in vitro. Biomaterials 1999, 20:1057-1062.

26. Desai MP, Labhasetwar V, Amidon GL, Levy RJ: Gastrointestinal uptake of biodegradable microparticles: effect of particle size. Pharm Res 1996, 13:1838-1845.

27. Holgadoa MA, Cozar-Bernala MJ, Salasa S, Arias JL, Alvarez-Fuentesa J, Fernandez-Avevaloa M: Protein-loaded PLGA microparticles angineered by flow focusing: Physicochemical characterization and protein detection by reversed-phase HPLC. International Journal of Pharmaceutics 2009, 380:147-154.

28. Almeria B, Deng W, Fahmy T, Gomez A: Controlling the morphology of electrospray-generated PLGA microparticles for drug delivery. Journal of Colloid and Interface Science 2010, 343:125-133.

29. Yao J, Lim LK, Xie J, Wang C: Characterization of electrospraying process for polymeric particle fabrication. J Aerosol Sciences 2008, 39:987-1002.

30. Quevedo E, Steinbacher J, McQuade DT: Interfacial polymerization within a simplified microfluidic device: capturing capsules. Journal of the American Chemical Society 2005, 127:10498-10499.

31. Feng $\mathrm{S}$, Huang G: Effects of emulsifiers on the controlled release of paclitaxel (Taxol) from nanospheres of biodegradable polymers. J Control Release 2001, 71:53-69.
32. Fessi H, Puixeux F, Devissaguet J.-P, Ammoury N, Benita S: Nanocapsule formation by interfacial polymer deposition following solvent displacement. International Journal of Pharmacy 1989, 55:R1-R4.

33. Gaumet M, Vargas A, Gurny R, Delie F: Nanoparticles for drug delivery: the need for precision in reporting particle size parameters. Eur J Pharm Biopharm 2008, 69:1-9.

34. Karnik R, Gu F, Basto P, Cannizzaro C, Dean L, Kyei-Manu W, Langer R, Farokhzad OC: Microfluidic platform for controlled synthesis of polymeric nanoparticles. Nano Lett 2008, 8:2906-2912.

35. Gaumet M, Gurny R, Delie F: Fluorescent biodegradable PLGA particles with narrow size distributions: preparation by means of selective centrifugation. Int J Pharm 2007, 342:222-230.

36. Sternling CV, Scriven LE: Interfacial turbulence: Hydrodynamic instability and the marangoni effect. AlChE Journal 1959, 5:514-523.

37. Berg J: Interfacial hydrodynamcis: an overview. Canadian Metallurgy Quarterly 1982, 21:121-136.

doi:10.1186/1477-3155-8-18

Cite this article as: Xie and Smith: Fabrication of PLGA nanoparticles with a fluidic nanoprecipitation system. Journal of Nanobiotechnology 2010 8:18.

\section{Submit your next manuscript to BioMed Central and take full advantage of:}

- Convenient online submission

- Thorough peer review

- No space constraints or color figure charges

- Immediate publication on acceptance

- Inclusion in PubMed, CAS, Scopus and Google Scholar

- Research which is freely available for redistribution

Submit your manuscript at www.biomedcentral.com/submit
C Biomed Central 